\title{
An Exploratory Study of Occupational and Secondary Traumatic Stress Among a Mid-sized Public Defenders' Office
}

Journal of Criminal Justice and Law: Official Journal of the Law and Public Policy Section of the Academy of Criminal Justice Sciences Volume 4, Issue 1, pp. 22-39 (2020)

\section{Elizabeth Dotson ', David C. Brody ', and Ruibin Lu "}

\begin{abstract}
The impact of stress on the mental and physical well-being of criminal justice professionals is of critical import for the effective operation of the criminal justice system. While a number of studies have examined various forms of stress among law enforcement and correctional officers, minimal research has examined the presence and impact of stressors among individuals working in the criminal courts. This exploratory study examines whether indigent defense attorneys suffer from occupational stress and secondary traumatic stress. A survey of attorneys from a mid-sized public defender's office were found to have symptoms of severe occupational stress as well as high levels of secondary traumatic stress. Furthermore, regression analyses indicated that secondary traumatic stress and severe occupational stress had significant negative impacts on attorney job satisfaction. Implications for these preliminary findings are discussed as well as recommendations to limit the negative impacts stress has on indigent defense attorneys.
\end{abstract}

Indigent defense attorneys are a central component in the operation of the criminal justice system. Federal, state, and local governments are constitutionally mandated to provide counsel to criminal defendants charged with felonies and serious misdemeanors. Absent the availability of a sufficient number of attorneys equipped and employed to effectively represent the indigent, the criminal courts would be unable to function.

While necessary, indigent defense practice, or public defense, involves significant challenges. These include high caseloads, underappreciation, relatively meager wages, and low-income, highly needy clients. Indigent defense attorneys have an ethical obligation to overcome these obstacles to zealously and effectively represent criminal defendants. The combination of working with needy, frequently traumatized clients in a highly adversarial atmosphere for an underfunded office have the potential to expose public defenders to high levels of occupational stress and secondary

\footnotetext{
'Washington State University, Pullman, WA, USA.

"Stockton University, Galloway, NJ, USA.

Corresponding Author:

David C. Brody, Washington State University, Pullman, WA 99164.

Email: brody@wsu.ed
}

The authors wish to express their appreciation to the blind reviewers of the original manuscript for their comments, which were helpful during preparation of the final version of the manuscript. 
Journal of Criminal Justice and Law:

traumatic stress. These stressors can lead to serious physical and mental maladies, as well as inhibit an attorney's ability to think clearly, modulate their emotions, and provide effective of representation (Krieger, 1998), and have a negative impact on the operation of the criminal court system. On the other hand, decreasing the levels of occupational stress and secondary trauma experienced by attorneys is likely to increase their mental well-being, health, and levels of job satisfaction.

This paper presents the results from an exploratory study which examines the levels of severe occupational stress and secondary traumatic stress experienced by a sample of public defenders in a single public defense office. Additionally, the relationship between job satisfaction and the measures of stress are explored, as are factors that might ameliorate the impact of high levels of stress. While exploratory, it adds to the literature by illustrating how occupational and secondary traumatic stress experienced by public defenders can be measured and recommending steps that be taken to ameliorate the impact these stressors have on individual attorneys as well indigent defense more broadly.

\section{OCCUPATIONAL STRESS}

The very nature of certain jobs can create high levels of tension and stress. Occupational stress describes the presence of extensive work demands and inadequate capacity to meet those demands (Janoo, Yap, \& Haron, 2014). This imbalance often results in adaptations that cause psychological or physiological suffering (Tennant, 2001). High levels of occupational stress have been found to have a negative impact on job performance (Gilboa, Shirom, Fried, \& Cooper, 2008), job satisfaction (Flannagan \& Flannagan, 2002), health (Goh, Pfeoffer, Zenios, \& Rajpal, 2015), and quality of life (Hassard, Visockaite, Dewe, \& Cox, 2017).

As knowledge and concern about occupational stress have risen, so too have the number of studies assessing its impact on workers in many industries. Research comparing stress levels across professions has found attorneys suffer from particularly high levels of occupational stress when compared to workers in other fields (Canadian Bar Association, 2012, p. 18; Otey, 2014; Freeman, 1999). In fact, high levels of stress are so commonplace in the practice of law, stress is considered an "occupational hazard" faced by attorneys (Sweeney, 1999; Norris \& Deeley, 2014). "The causes and manifestations of lawyer stress are numerous and often overwhelming" (Thornhill, 2017, p. 115), "an inherent and inescapable part of practicing law"(Warren, 1998, p. 5) and "a constant reality in the everyday practice of a lawyer . .." (Bibelhausen, Bender, \& Barrett, 2015, p. 932). Research has found there to be a multitude of causes for stress experienced by attorneys, including firm deadlines, adversariness, constant scrutiny, and high expectations from clients (Alfini \& Van Vooren, 1995; Blumenthal, 2016; Otey, 2014;).

Among the various areas of law, representing indigent criminal defendants is perhaps the most stressful (Elwork, 1995, p. 22; Schenker, Eaton, Green, \& Samuels, 1997). Besides the stressors just mentioned-many of which are felt intensely by other types of criminal defense attorneys-several factors specific to indigent defense practice can exacerbate the stress felt by a lawyer. These stressors include frequent conflict with prosecuting attorneys and judges; high caseloads; numerous jury trials; dissatisfied, cynical, and untrusting clients; lack of support from the public; and vicarious trauma (Lynch, 1997). 
Several qualitative studies document the intense stress inherent in indigent defense work. A 1987 study by Lisa Mclntyre reported on numerous interviews with both current and former attorneys from the Cook County Office of Public Defense. The study found high levels of stress, cynicism, and disillusionment they experienced on the job. Factors leading to these conditions included high caseloads; disrespect by clients, adversaries, judges, and society; and frustration with the criminal justice system (McIntyre, 1987).

In the late 1990s David Lynch published several studies that examined the occupational stress experienced by public defenders. In a qualitative study that focused on public defenders in New York state and the Carolinas, Lynch (1998) reproduced extensive quotes from interviews conducted with public defense attorneys. The interviews revealed several recurring causes of stress, including conflicts with clients, arguments with unreasonable prosecutors, and high caseloads (Lynch, 1998, p. 476).

Paul Wice (2005) published the results of an in-depth qualitative study of the Essex County, New Jersey, Regional Public Defender's Office. Wice found the office's attorneys to be suffering from high levels of stress. He concluded that the stress was caused by many factors, including heavy caseloads, unreasonable demands to complete cases expeditiously, and clients' negative stance toward their appointed counsel (Wice, 2005). Attorneys were especially disturbed by their clients' unwillingness to take advice, their lack of trust in the office and the criminal justice system, and the frequent lies they told their lawyer.

In addition to these qualitative studies, several quantitative studies have been published. In 1997, surveying a sample of public defenders in New York state, David Lynch focused on two questions: what stressors do public defenders experience most frequently, and what is the intensity of each stressor? After determining the frequency and intensity of a set of potential stressors, Lynch identified seven stressors that occurred frequently and were very intense. These items were an excessive amount of work to do, the unpredictability of trials occurring, the absence of a viable defense at trial, the need to satisfy conflicting parties, upset and angry clients and families, arguments with prosecutors, and the lack of a realistic option to take cases to trial due to draconian sentences (Lynch, 1997, p. 26-27).

Choo, Shulman, and Selva (2009) surveyed public defenders in Tennessee about occupational stress. Much of their research focused on the relationship between public defenders' occupational stress and several demographic characteristics. They found that new attorneys and veteran attorneys experienced relatively high levels of stress when compared to attorneys at mid-career (Choo, Shulman, \& Selva, 2009, p. 975). The researchers also observed that compared to non-white attorneys, white public defenders experienced significantly higher levels of stress from heavy caseloads, insufficient resources, and the inability to make a difference in a client's life. With regards to gender, while the authors found that both male and female attorneys suffered from high occupational stress, the specific items causing high stress differed by gender. Women reported more frustration and stress regarding corruption in the system while male defenders had higher stress scores related to having too many cases and working too many hours (Choo, Shulman, \& Selva, 2009, p. 977.)

The studies just summarized focused on numerous factors that cause indigent defense attorneys to experience occupational stress. Regardless of the specific items that are causing stress, the effects that high levels of stress have on an attorney's perception of his or her job are of critical importance. 
Journal of Criminal Justice and Law:

\section{SECONDARY TRAUMATIC STRESS}

Secondary traumatic stress (STS) is "the natural consequent behaviors and emotions resulting from knowing about a traumatizing event experienced by a significant other-the stress resulting from helping or wanting to help a traumatized or suffering person" (Figley, 1995, p. 7). STS can afflict professionals who have empathy for their traumatized clients and invest much of themselves in trying to help the traumatized person or people. Symptoms associated with STS closely parallel those experienced by individuals suffering from post-traumatic stress disorder, including intrusive thoughts, sleep disturbances (difficulty with sleep onset, nightmares), hypervigilance, withdrawal, avoidance, lessened affect, and increased tension (Albert, 2009; APA, 2013; Figley, 1995).

STS has been studied across a variety of professions, particularly "helping professions." Research has found it to be particularly common among helping professionals, such as social workers, and medical personnel, mental health professionals, first responders, and crisis workers (Bride, 2007; Osofsky, Putnam, \& Lederman, 2008). Research on STS has centered around two general fields: mental health professionals and crisis workers. Research has found that police officers, firefighters, paramedics, emergency medical technicians, nurses, and child welfare workers are fields that are highly susceptible to being traumatized simply through learning about a traumatic event from a client, victim, or graphic material (Bryant \& Harvey, 1996; Chrestman, 1995; Cornille \& Meyers, 1999; Marmar, Weiss, Metzler, Ronfeldt, \& Foreman, 1996).

A small amount of research has consistently found that attorneys specializing in certain areas are highly susceptible to STS. Attorneys who work closely with traumatized clients and work in an adversarial environment on a daily basis are especially vulnerable to STS. Specifically, attorneys whose practices focus on family law (Borbst, 2014), immigration law (Piwowarcyzy et al. 2009), and criminal defense (Murray \& Royer, 2004) are at significant risk of STS.

Levin and Griesberg (2003) compared levels of STS experienced by attorneys from public defender offices, as well as from agencies specializing in domestic violence and criminal law, to levels found in social workers and mental health professionals who work with victims of child abuse. Researchers found that the attorneys had much higher levels of STS than the mental health professionals and social workers.

Professors Vrklevski and Franklin (2008) explored vicarious trauma in the legal profession. A random sample of Australian criminal law and noncriminal law solicitors completed questionnaires that asked about, among other things, vicarious trauma. The authors found that criminal lawyers had much higher levels of vicarious trauma than non-criminal attorneys.

Levin et al. (2011) compared the levels of secondary trauma among attorneys and administrative support staff who worked in public defender offices across the state of Wisconsin. The study found that the attorneys demonstrated significantly higher levels of secondary traumatic stress than non-attorney staff.

There are a number of reasons why one might expect public defense attorneys to suffer from high levels of STS. As stated by Vrklevski and Franklin (2008, p. 107), "[p]ublic defenders feel the impact of trauma on a daily basis. Overwhelming emotions, injustice, despair, rage, self-harm, are other self-destructive behaviors are exposed and reenacted in intricate detail in the hallowed halls of justice (Murray \& Royer, 2004)."

In addition to vicariously experiencing trauma, public defense attorneys must also deal with the reality that they possess limited ability to help clients overcome trauma. Although trained to 
remain detached from the emotions being experienced by clients, in practice these attorneys must engage and empathize with them sufficiently so that the client feels able to trust and confide in their attorney (Ellman, 1992). While it is normal for attorneys to show empathy toward their clients and crime victims, and in fact very helpful to their clients, such feelings may have a detrimental impact on an attorney's psyche and negatively impact their representation (Murdoch, 2000). Attorneys have an ethical obligation to zealously represent their clients. The role of zealous advocacy forces attorneys to subordinate their emotional response to the more objective needs of the case (Norton, Johnson, \& Woods, 2015). Such repression increases the impact stressors have on a person (Bandes, 2006). Moreover, individuals who have a greater capacity for empathy for a traumatized client are at greater risk to suffer from STS due to this inner conflict (Figley, 1995; Ludick \& Figley, 2016).

The nature of the work, when combined with extremely high caseloads maintained by most public defenders, provides a ripe environment for STS. This is exacerbated by the fact that individual attorneys and public defender offices lack the resources to effectively address the needs of traumatized clients. Moreover, due to a lack of training or education concerning how to deal with trauma public defenders are placed in the position of having to personally work through client trauma and emotional needs without the time or capacity to do so.

\section{JOB SATISFACTION}

While a high level of stress in and of itself impacts public defenders' ability to effectively perform their jobs and continue to represent indigent defendants, the effect stress has on other aspects of occupational psychology is of equal concern. In particular, public defender job satisfaction, which is frequently impacted by high levels of stress, is of paramount importance.

The literature on attorneys' job satisfaction often falls into one of two categories (Dinovitzer \& Garth, 2007). One body of research presents the popular view of lawyers as being quite miserable and highly dissatisfied in their career. This narrative presents lawyers as battling depression, drug abuse, alcoholism, and other physical and emotional maladies (Krill, Johnson, \& Albert, 2016; Cuban, 2017). The literature reflecting this body of research is generally published in the popular press and legal periodicals (i.e., State Bar publications) and focuses on how to improve the well-being of attorneys (Eaton, 2014; Kuzemka, 2013; Livingston, 2002; Lloyd \& Hats, 2008). Many studies in this category have been found to suffer from methodological shortcomings such as non-random samples, low response rates, or failure to report demographic or methodological details (Hull, 1999; Dinovitzer \& Garth, 2007).

The other body of research uses widely accepted social science methods and is primarily published in peer-reviewed journals or respected law reviews (Dinovitzer \& Garth, 2007). This research has predominantly found that lawyers are generally satisfied with their jobs, with job satisfaction levels akin to those found in non-legal careers (Organ, 2010; Patel, Rajderkar, \& Niak, 2012). Jerome Organ (2010) examined 44 studies conducted between 1994 and 2010 that examined attorney job satisfaction. Each of the 38 studies reviewed reported that at least $50 \%$ of the attorneys were satisfied with their jobs. Additionally, Organ calculated that the average percent of attorneys across a wide variety of legal specialties satisfied with their jobs was an impressive 78.9\% (Organ, 2010, p. 262).

Several studies have examined the levels of job satisfaction experienced specifically by public defenders. For example, Donna Hall (1995) found that overall, both male and female public 
defense attorneys had similar levels of job satisfaction. The components of their jobs that proved satisfying, however, differed across gender. While the level of job satisfaction felt by female attorneys centered around the issues of promotional opportunities and manageable workloads, male attorneys were more concerned with support from their co-workers and perceived level of prestige associated with public defense work (Hall, 1995, p. 131).

As with other areas, the research on attorney job satisfaction has examined relationships between satisfaction levels and items such as gender, race, salary, field of law, and years of experience. The research has not, however, closely scrutinized the impact of occupational stress on how lawyers view their jobs. The present study seeks to explore the linkages between occupational stress and job satisfaction in a specific area of the law, indigent defense.

\section{THE PRESENT STUDY}

The present study will examine the relationships between STS, severe occupational stress, and job satisfaction among public defense attorneys. The study advances our understanding of the relationships between occupational stress, secondary traumatic stress, and job satisfaction among indigent defense attorneys. Based on previous research, the following hypotheses were developed:

Hypothesis 1: Attorneys with higher levels of severe occupational stress will suffer from higher levels of secondary traumatic stress.

Hypothesis 2: Attorneys with higher levels of severe occupational stress will have lower levels of job satisfaction when controlling for gender, experience, and levels of STS.

Hypothesis 3: Attorneys with higher levels of STS will have lower levels of job satisfaction when controlling for gender, experience, and levels of severe occupational stress.

\section{METHODS}

The data for this study was obtained from a survey administered to the attorneys at a moderate-sized public defender's office in the western United States. All non-supervisory attorneys in the office were asked to complete an electronic survey regarding various aspects of their jobs. Survey invitations were sent to 56 attorneys via e-mail. Thirty-five attorneys returned completed surveys for a response rate of $62.5 \%$. All 35 respondents identified themselves as being white, with 19 self-identifying as male. Descriptive statistics for the variables used in the analysis are presented in Table 1.

\section{Dependent Variables}

Two dependent variables were examined in this study. The first, Secondary Traumatic Stress, was measured using an additive scale developed by Bride and his colleagues (2004). Using a Likerttype scale with responses ranging from 1 (never) to 5 (always) respondents were asked how often they experienced 17 specific conditions during the past week. Individual scaled scores ranged from 18-75 with a Cronbach's alpha of 91, indicating great internal reliability. 
The second dependent variable, job satisfaction, was measured using a 14-item scale. This additive scale was based on the scale developed to measure attorney job satisfaction by the NALP Foundation for Law Career Research and Education and the American Bar Foundation (Dinvoitzer et al., 2014). Using a five-point Likert-type scale ( $1=$ very dissatisfied to $5=$ very satisfied $)$, respondents were asked to indicate their level of satisfaction with 14 components of being an attorney. Potentially, scale totals could range from 14 ( 1 on all components) to 70 ( 5 on all components). The actual range was 32-70, with a mean score of 48.75 .

Table 1: Descriptive Statistics

\begin{tabular}{ll}
\hline Gender & Male $=17$ \\
& Female $=15$ \\
Years at Public Defender Office & $0-5$ years $=7$ \\
& $6-10$ years $=9$ \\
& More than 10 years $=16$ \\
Secondary Traumatic Stress & Mean $=46.06$ \\
Severe Occupational Stressors & Mean $=2.88$ severe stressors present \\
Job Satisfaction & Mean $=48.79$ \\
\hline
\end{tabular}

\section{Independent Variables}

The key exogenous variable used in this study is the level of severe occupational stress experienced by public defenders. The measure for occupational stress was obtained through a two-step process. Seven potential stressors were measured across two dimensions, frequency of occurrence and intensity of the stress experienced (Lazarus \& Folkman, 1984). Frequency was measured on a five-point Likert-type scale (never-always). The intensity of the stress experienced was measured on a three-point scale (low, medium, and high).

The next step in the process involved identifying stressors that respondents indicated occurred always or often and had high or medium levels of intensity. Items that met these criteria were labeled as "severe stressors," (coded 1 , non-severe stressors 0. .) In other words, if a respondent reports always or often experiencing a type of stressor at high or medium levels, this type of stressor is rated as a "severe stressor" for the respondent. Respondents' scores for each of the seven stressors were then added together for a "severe stress scale," which is used as an independent variable in multivariate analysis.

\section{Data Analysis}

The analysis in the study consists of three parts. First, summary statistics were computed for all variables of intertest, including the scales developed to measure severe occupational stress, secondary traumatic stress, and job satisfaction (see Table 1). The second part of the analysis involved developing multivariate models to test the hypotheses presented above. Additionally, coefficients obtained from the multivariate models were used to examine indirect effects on the dependent variables. The third part of the analysis involved considering the responses to openended questions provided by respondents to shed additional light on the relationships observed in the quantitative analysis. 
Journal of Criminal Justice and Law:

\section{RESULTS}

\section{Secondary Traumatic Stress}

Descriptive statistics for each symptom of the Secondary Traumatic Stress Scale are presented in Table 2. Symptoms that had a mean score of 3 (experienced by respondents occasionally, often, very often on a weekly basis) are considered to be problematic (Bride, 2003). The most frequent symptom experienced by respondents was “I thought about my work with clients when I didn't intend to." Four other symptoms, "I had trouble sleeping," "I was easily annoyed," "I had trouble concentrating," and "I was less active than usual," were routinely experienced by a majority of respondents. On the other hand, the three least frequent symptoms reported by respondents were, "It seemed as if I was reliving the trauma(s) experienced by my client(s)," "My heart started pounding when I thought about my work with clients," and "I had disturbing dreams about my work with clients." While the frequency of individual symptoms of STS are interesting, for research purposes the index scores have been placed into a normative scale (Bride, 2007) to provide a more usable overarching view of the levels of STS experienced by individuals.

Table 2: Descriptive Statistics of Secondary Traumatic Stress Components

\begin{tabular}{lcc}
\hline & & $\begin{array}{c}\text { Std. } \\
\text { Deviation }\end{array}$ \\
\hline I felt emotionally numb & Mean & 1.09 \\
My heart started pounding when I thought about my work with clients & 2.03 & 1.06 \\
It seemed as if I was reliving the trauma(s) experienced by my client(s) & 1.97 & 1.20 \\
I had trouble sleeping & 3.42 & 1.28 \\
I felt discouraged about the future & 2.67 & 1.22 \\
Reminders of my work with clients upset me & 2.39 & 1.06 \\
I had little interest in being around others & 2.91 & 1.40 \\
I felt jumpy & 2.33 & 1.16 \\
I was less active than usual & 3.15 & 1.23 \\
I thought about my work with clients when I didn't intend to & 3.52 & 1.20 \\
I had trouble concentrating & 3.18 & 1.04 \\
I avoided people, places, or things that reminded me of my work with clients & 2.45 & 1.37 \\
I had disturbing dreams about my work with clients & 2.16 & 1.25 \\
I wanted to avoid working with some clients & 2.88 & 1.11 \\
I was easily annoyed & 3.18 & 1.10 \\
I expected something bad to happen & 2.82 & 1.31 \\
I noticed gaps in my memory about client sessions & 2.55 & 1.39 \\
Overall Mean & 46.06 &
\end{tabular}

The aggregation of the individual responses within the STS scale is presented in Table 3. Each respondent's total STS score was calculated by summing the response value for each item (the 
highest score possible being 85 and the lowest score being 18). Scores on the STS scale ranged from 18-75, with the average score being 46.06. A person is considered to suffer from STS if their aggregate score from the 17-question scale is 38 or greater (Bride, 2007). Importantly, a significant majority of respondents indicated moderate, high, or severe levels on the STS scale. This result corresponds with the theoretical arguments and quantitative findings that criminal defense attorneys are highly susceptible to secondary traumatic stress. From the data, it is fair to conclude that the presence of STS among public defenders is a concern that needs addressing.

Table 3: Secondary Traumatic Stress Scale

\begin{tabular}{lc} 
Little or no STS $(<28)$ & $9 \%$ \\
Mild STS (28-37) & $13 \%$ \\
Moderate STS (38-43) & $28 \%$ \\
High STS (44-48) & $19 \%$ \\
Severe STS (> 48) & $31 \%$ \\
Observed Range 18-75 & \\
Mean 46.06 (SD 12.93) & \\
Cronbach's Alpha .91 & \\
\hline
\end{tabular}

\section{Severe Occupational Stress}

As discussed by Professors Lu and Brody (2019), severe occupational stress was a significant problem experienced by respondents. Overall, nearly $90 \%$ of the attorneys suffered severe stress involving at least one of the seven stressors calculated. Over half of respondents suffered severe stress from the size of their caseload, the emotional toll of the job, or the lack of resources available to perform their duties (see Table 4).

Table 4 Occupation Related Stressors

\begin{tabular}{lccc}
\hline & FREQUENCY & INTENSITY & \\
\hline & Occurs Often or & Moderate or High & Severe \\
& Always & Intensity & Stressor \\
Caseload & $68 \%$ & $94 \%$ & $66 \%$ \\
Emotional toll of the job & $56 \%$ & $88 \%$ & $56 \%$ \\
Lack of resources & $53 \%$ & $72 \%$ & $53 \%$ \\
Pressure to handle case quickly & $46 \%$ & $76 \%$ & $46 \%$ \\
Work hours & $31 \%$ & $54 \%$ & $31 \%$ \\
Poor relationship w prosecutor & $21 \%$ & $56 \%$ & $21 \%$ \\
Unreasonableness of supervisor & $12 \%$ & $52 \%$ & $12 \%$ \\
\hline
\end{tabular}

To determine the overall amount of serious stress experienced by respondents, an additive index made up of each stressor was developed, with each stressor being labeled 0 (not severe) or 1 (severe). The values of the seven items for each respondent were then added together giving us a severe stress scale. The severe stress scores for individual attorneys ranged from 0 to 7 with a mean of 2.88, indicating that on average, attorneys suffered from nearly three serious stressors (see Table 5). 
Journal of Criminal Justice and Law:

Table 5: Number of Severe Stressors Experienced by Attorneys

\begin{tabular}{ccc}
\hline Severe Stressors Present & Frequency & Percent \\
\hline 0 & 4 & 11.8 \\
1 & 3 & 8.8 \\
2 & 6 & 17.6 \\
3 & 10 & 29.4 \\
4 & 4 & 11.8 \\
5 & 6 & 17.6 \\
6 & 0 & 0 \\
7 & 1 & 2.9 \\
\hline
\end{tabular}

\section{Job Satisfaction}

Table 6 provides the mean scores for each of the 14 job satisfaction components, as well as the job satisfaction composite index score. Overall, respondents reported that they are generally satisfied with their jobs as indicated by the index mean of 48.75. On average, the most satisfying aspect of the job was job security, followed by the job's intellectual challenge, and relationships with colleagues. The items that respondents were primarily dissatisfied with were control over the amount of work they were required to do, lack of recognition for the work they did, and opportunities for advancement.

\section{Table 6: Job Satisfaction Index and Component Descriptive Statistics}

\begin{tabular}{lcc}
\hline Component & Mean & S.D. \\
\hline Job security & 4.30 & 0.88 \\
Intellectual challenge & 4.21 & 0.89 \\
Relationships with colleagues & 3.97 & 1.31 \\
Substantive area of your work & 3.91 & 0.95 \\
Tasks you perform & 3.85 & 0.97 \\
Level of responsibility & 3.67 & 1.16 \\
Opportunities to build skills & 3.67 & 1.08 \\
Control over the how work is performed & 3.61 & 1.06 \\
Salary & 3.33 & 1.14 \\
Performance evaluation & 3.21 & 1.02 \\
Work-life balance & 3.06 & 1.30 \\
Opportunities for advancement & 2.82 & 1.36 \\
Recognition for work & 2.79 & 1.39 \\
Control over the amount of work & 2.36 & 1.19 \\
\hline
\end{tabular}




\section{Correlations}

Pearson correlations were computed to determine whether bivariate relationships are present between the dependent and control variables. As shown in Table 7, this analysis indicated that severe occupational stress and secondary traumatic stress have a strong, statistically significant positive relationship with each other $(r=.62, p .<.01)$. Equally significant were the relationships job satisfaction has with the two stress measures. As predicted, job satisfaction was negatively related to severe occupational stress $(r=-.36, p .<.05)$ and secondary traumatic stress $(r=-.56, p .<.01)$. Two control variables found by prior research to be related to the levels of stress and job satisfaction, gender, and years of experience, are not significantly related to any of our measures of interest.

Table 7: Correlations

\begin{tabular}{lccccc}
\hline & $\begin{array}{c}\text { Severe } \\
\text { Occupational } \\
\text { Stress }\end{array}$ & $\begin{array}{c}\text { Secondary } \\
\text { Traumatic Stress }\end{array}$ & $\begin{array}{c}\text { Job } \\
\text { Satisfaction }\end{array}$ & $\begin{array}{c}\text { Gender } \\
\text { Years at } \\
\text { PD } \\
\text { Office }\end{array}$ \\
\hline $\begin{array}{l}\text { Severe Occupational } \\
\text { Stress }\end{array}$ & & $.62^{* *}$ & $-.36^{*}$ & .46 & -.26 \\
$\begin{array}{l}\text { Secondary Traumatic } \\
\text { Stress }\end{array}$ & $.62^{* *}$ & & $-.56^{* *}$ & .34 & -.25 \\
Job Satisfaction & $-.36^{*}$ & $-.56^{* *}$ & & & .65 \\
Gender & .46 & .34 & .65 & & .89 \\
Years at PD Office & -.26 & -.25 & .89 & -.37 & -.37 \\
\hline
\end{tabular}

\section{Regression Analysis}

In order to more accurately determine if the relationships discussed above are spurious or suppressed, two simple multivariate ordinary least squares (OLS) models were computed. The first model, presented in Table 8, shows the results of the multivariate analysis with secondary traumatic stress as a dependent variable. The model was statistically significant and explained about $39 \%$ of the variance in STS. As hypothesized, attorneys with higher levels of occupational stress suffered from higher levels of STS, controlling for gender and years at the public defender's office. Neither gender nor experience had a statistically significant impact on STS.

Table 8: Ordinary Least Squares Analysis Predicting Secondary Traumatic Stress

\begin{tabular}{lccc}
\hline & B & Std. Error & Beta \\
\hline Severe Occupational Stress & 4.483 & 1.157 & $.562^{* *}$ \\
Gender & 4.609 & 4.089 & .179 \\
More than 10 years at PD & -4.026 & 4.168 & -.152 \\
Adjusted $\mathrm{R}^{2}=.393 \mathrm{~F}=7.47^{* *}$ & & &
\end{tabular}


The second OLS model tested the impact secondary traumatic stress and severe occupational stress had on job satisfaction. As shown in Table 9, the model was statistically significant and explained about $31 \%$ of the variance in job satisfaction. As found in bivariate analysis, secondary traumatic stress had an extremely strong, significant relationship with job satisfaction $(\beta=-.64, p$. $<.01)$. As predicted, attorneys with higher levels of STS had lower levels of job satisfaction. On the other hand, public defenders suffering from severe occupational stress did not have a significant degree of job dissatisfaction, contrary to our hypothesis and the bivariate results. This indicates that the bivariate relationship between occupational stress and job satisfaction found in the Pearson correlation analysis was spurious and rendered insignificant when controlling for STS, gender, and years at the public defender's office. It is important to note, however, that while severe occupational stress did not have a direct effect on job satisfaction, it did have a moderate indirect effect (.36) through its relationship with STS. This relationship is depicted in in the path model depicted in Figure 1. While this association is moderate, it is very strong for an indirect relationship. Future research should use larger samples to better examine the presence of indirect relationships.

Table 9: Ordinary Least Squares Analysis Predicting Job Satisfaction

\begin{tabular}{lccc}
\hline & B & Std. Error & Beta \\
\hline Secondary Traumatic Stress & -.440 & .140 & $-.642^{* *}$ \\
Severe Occupational Stress & -.245 & 1.052 & -.045 \\
Gender & .364 & 3.050 & .021 \\
More than 10 years at PD & -3.972 & 3.090 & -.219 \\
Adjusted $\mathrm{R}^{2}=.312 \quad \mathrm{~F}=4.41^{*}$ & & & \\
\hline
\end{tabular}

$* p<.05, * * p<.01$

Figure 1. Path Model of Impact of Stressors on Job Satisfaction

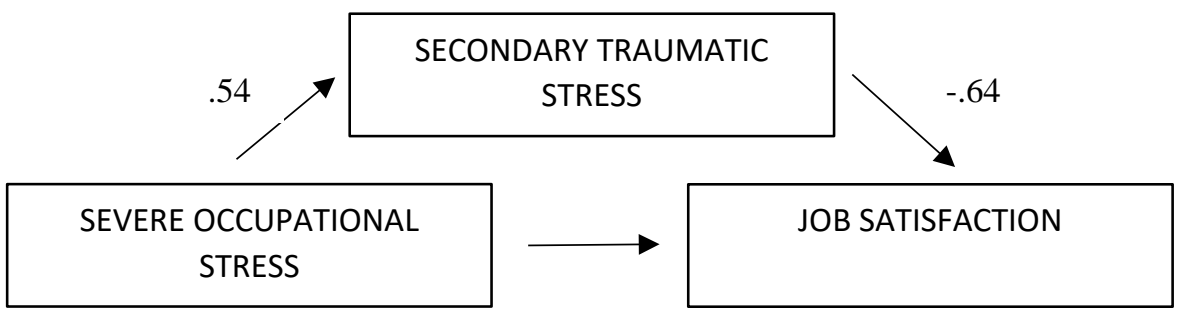

\section{DISCUSSION AND CONCLUSIONS}

Public defenders are an integral part of the criminal justice system, yet their needs and responsibilities are often overlooked through systemwide emphasis on efficiency over effectiveness. These discrepancies between goals and ability can lead to increased incidence of job-related stress among public defenders. These stresses, coupled with consistent and continued 
exposure to the traumatic experiences of clients and victims, create a situation that is ripe for high rates of secondary traumatic stress and the resulting symptomatology.

Findings of this exploratory study confirmed our three hypotheses. Attorneys with higher levels of severe occupational stress will suffer from higher levels of secondary traumatic stress $(\mathrm{H} 1)$; attorneys with higher levels of severe occupational stress will have lower levels of job satisfaction when controlling for gender, experience, and levels of STS (H2); and attorneys with higher levels of STS will have lower levels of job satisfaction when controlling for gender, experience, and levels of severe occupational stress (H3). Juxtaposed to this, however, there were also relatively high rates of job satisfaction reported, despite the high reports of STS indicators and frequency of job-related stress. This speaks to the complexity of the relationship between satisfaction and stress in the public defender work environment and points to the need for additional research to clarify these findings.

There are several limitations regarding the research findings presented within this paper. The exploratory nature of this study, the low number of participants, and the single public defender office represented within the sample create a limited scope for the statistical power of analysis as well as the generalizability of these findings. Additionally, future research should examine additional measures to facilitate a deeper understanding of the findings presented above. These measures, which include specific work hours, stress tolerance, mental health diagnoses, sleep data, substance abuse, and type of caseload could add depth to the analysis and serve to increase the body of literature regarding these and other factors involving the impact of secondary traumatic stress on the work and well-being of attorneys.

In spite of these limitations, the current study found that indigent defense attorneys suffer from occupational and trauma related stressors. While having to deal with stress may be unavoidable for public defenders, it is possible to effectively deal with so as to prevent acute psychic maladies. At the forefront of any effort to help not only public defenders, but all attorneys, is educating lawyers about the nature of occupational and secondary traumatic stress and providing information about ways in which lawyers can overcome them and have healthy, productive careers.

Although law schools do an excellent job of teaching substantive procedural areas of the law, as well as training students to be dispassionate and to "think like lawyers," overall law schools do not do a good job of preparing future lawyers to cope with stress and the psychic maladies they may experience due to the nature of their legal practice. This void in preparation creates an opportunity to ameliorate the negative impact of exposure to stress through education. While students preparing to enter other helping professions, particularly social work and psychology, are "'trained to expect transference and countertransference reactions in their relations with their clients,' law students are far less prepared for the psychosocial aspects of their profession." (Otey, 2014, p. 184, quoting Silver, Portnoy, and Peters, 2004, pp. 872-73).

Due to this lack of preparation for the psychosocial impact of working with traumatized clients and the inherent occupational stress experienced by attorneys, law students frequently leave law school ill prepared to cope with these aspects of a career in law. (Otey, 2104). These shortcomings, however, can be addressed in any number of ways not only by law schools, but also, importantly, by employers, professional organizations, and bar associations (Alfini and Van Vooren, 1995).

Law schools should examine the use of law clinics and professionalization seminars to educate their students on the impact stress and emotional hazards have on attorneys (Bennett, 2010). 
Work in clinical settings, particularly those involving criminal defense, family law, and immigration, can be effective in educating future attorneys on trauma-informed lawyering (Katz and Haldar, 2016). Prior to working directly with clients, students can be taught about the psychological impact working with traumatized clients can have on an attorney. This lays the groundwork for debriefing sessions and psycho-educative discussions between students and qualified instructors about their experiences, and how these experiences correspond to the relevant scholarship. This mode of educating can help students understand that they must be aware of the potential impact working with traumatized clients can have on practicing lawyers. (Bennett, 2010).

Scholars have also advocated for the use of psychoeducation instruction as part of professional development instruction (Otey, 2014). "This education, comprised of an understanding of the psychological dynamics at play in the lawyer-client relationship, the effects of stress and trauma on the individual's psyche, and the expected physiological reaction, is a fundamental component to thriving [professionally]" (Otey, 2014, p. 183). Such classes can instruct on the impact burnout, occupational stress, and traumatic stress can have one's health and legal practice. By providing education to future attorneys prior to them entering the profession, law schools can ameliorate problems encountered by the uninformed attorney when faced with stressors and traumatized clients. (Bennett, 2010).

While law schools can expose students to these matters, it is important that education and assistance not stop at graduation. In fact, there are opportunities for practice area-specific education could be provided, if not mandated, for attorneys who work with traumatized populations. Medium and large public defender offices can provide periodic workshops covering the inherent emotional dangers in working with traumatized clients and their families. Such workshops, which can be presented in person or through synchronous or asynchronous video, can be geared toward the issues particular to attorneys working in indigent defense.

Beyond offerings in individual public defender offices, state and national indigent defense associations can prepare and make available for distribution workshops and courses aimed for their members. National organizations, including the National Association of Criminal Defense Lawyers (NACDL), the National Legal Aid \& Defender Association (NLADA), the American Council of Chief Defenders, and the Criminal Law Section of the American Bar Association, which routinely provide trainings and workshops geared toward indigent defense attorneys, are well positioned to take the lead in this effort.

State and local bar associations can also assist in educating their members regarding the emotional aspect of working with traumatized clients and best practices for limiting its personal and professional impact on attorneys (Alpert, 2009). As part of continuing legal education (CLE) programs, bar associations can either develop or license training materials that members can take to fulfill CLE requirements. Beyond filling these requirements, leaning about and understanding the dangers of occupational and secondary traumatic stress can greatly enhance the quality of life experienced by attorneys, and leave them better equipped to effectively represent their clients.

\section{Declaration of Conflicting Interests}

The author declares no potential conflicts of interest with respect to the research, authorship, and/or publication of this article. 


\section{Funding}

The author received no financial support with respect to the research, authorship, and/or publication of this article.

\section{Sources Cited}

Albert, L. (2009, Winter/Spring). Keeping legal minds intact: Mitigating compassion fatigue among government lawyers. The Wisconsin Defender, 17(1), 1-4.

Alfini, J. J., \& Van Vooren, J. N. (1995). Is there a solution to the problem of lawyer stress? The law school perspective. Journal of Law \& Health, 10, 61-67.

American Psychiatric Association. (2013). Diagnostic and statistical manual of mental disorders (5th ed.). Arlington, VA: American Psychiatric Association.

Bandes, S. (2006). Repression and denial in criminal lawyering. Buffalo Criminal Law Review, 9, 339.

Bibelhausen, J., Bender, K. M., \& Barrett, R. (2015). Reducing the stigma: The deadly effect of untreated mental illness and new strategies for changing outcomes in law students. William Mitchell Law Review, 41, 918-938.

Blumenthal, M. (2016). The giant who goes with them wherever they go: Lawyers and stress. West Virginia Lawyer, (July-September), 16-18.

Braun, S. L. (1998). What you need to know: Lawyers and mental health in a nutshell, Houston Lawyer, 35 (May/June), 36-43.

Bride, B., Robinson, M., Yegidis, B., \& Figley, C. (2004). Development and validation of the secondary traumatic stress scale. Research on Social Work Practice, 14, 27-35.

Bride, B. (2007). Prevalence of secondary traumatic stress among social workers. Social Work, 52, 63-70.

Brobst, J. (2014). The impact of secondary traumatic stress among family attorneys working with trauma-exposed clients: Implications for practice and professional responsibility. Journal of Health \& Biomedical Law, 10, 1-51.

Bryant, R., \& Harvey, A. (1996). Posttraumatic stress reactions in volunteer firefighters. Journal of Traumatic Stress, 9, 51-63.

Canadian Bar Association. Survey of lawyers on wellness issues, final report. Ottawa, ON: Canadian Bar Association.

Chrestman, K. (1995). Secondary exposure to trauma and self-reported distress among therapists. In B.H. Stamm (Ed.), Secondary traumatic stress: Self care issues for clinicians, researchers, and educators (pp.29-36). Derwood, MD: Sidran Press.

Choo, T. M., Shulman, W., \& Selva, L. (2009). Stress levels among public defenders in Tennessee. Criminal Law Bulletin, 45, 962-981.

Cornille, T. A., \& Meyers, T. W. (1999). Secondary traumatic stress among child protective service workers: Prevalence, severity and predictive factors. Traumatology, 5, 1-16.

Cuban, B. (2017). The addicted lawyer: Tales of the bar, booze, blow \& redemption. Brentwood, TN: Post Hill Press.

Elwork, A. (1995). Stress management for lawyers. North Wales, PA: Vorkell Group.

Dinovitzer, R., \& Garth, B. G. (2007). Lawyer satisfaction in the process of structuring legal careers. Law \& Society Review, 41, 1-50.

Eaton, M. W. (2014). Ethics \& law: Do the right thing. Texas Bar Journal, 77, 598-601. 
Journal of Criminal Justice and Law: Official Journal of the Law and Public Policy Section of the Academy of Criminal Justice Sciences

Ellmann, S. (1991). Empathy and approval. Hastings Law Journal, 43, 991.

Flanagan, N. A., \& Flanagan, T. J. (2002). An analysis of the relationship between job satisfaction and job stress in correctional nurses. Research in Nursing \& Health, 25, 282-294.

Freeman, C. (1999). Stress! Stressed! Stressed Out! Alabama Lawyer, 60, 332-333.

Gilboa, S., Shirom, A., Fried, Y., \& Cooper, C. (2008). A meta-analysis of work demand stressors and job performance: Examining main and moderating effects. Personnel Psychology, 61, 227271.

Goh, J., Pfeffer, J., and Zenios, S. A. (2015). Workplace stressors and health outcomes: Health policy for the workplace. Behavioral Science \& Policy, 1, 43-52.

Gordon, R. W. (1988). The independence of lawyers. Boston University Law Review, 68, 1-83.

Hall, D.L. (1995). Job satisfaction among male and female public defense attorneys. Justice System Journal 18, 121-39.

Harris, L.C. (2002). The emotional labour of barristers: An exploration of emotional labour by status professionals. Journal of Management Studies, 39, 553-84.

Hassard, J., Teoh, K. R. H., Visockaite, G., Dewe, P., \& Cox, T. (2018). The cost of work-related stress to society: A systematic review. Journal of Occupational Health Psychology, 23, 1-17.

Hull, K. E. (1999). Cross-examining the myth of lawyers' misery. Vanderbilt Law Review, 52, 971983.

Jannoo, Z., Yap, B. W., \& Haron, H. (2015). Evaluation of the job stress survey and its factor structure. Quality \& Quantity, 49, 711-726.

Krill, P. R., Johnson, R., Albert, L. (2016). The prevalence of substance use and other mental health concerns among American attorneys. Journal of Addiction Medicine, 10, 46-52.

Kuzemka, K. (2013). Addiction: What to do? Nevada Lawyer, 21 (December), 21-22.

Lazarus, R. S., \& Folkman, S. (1984). Stress, appraisal, and coping. New York: Springer.

Levin, A., \& Greisberg, S., (2003). Vicarious trauma in attorneys. Pace Law Review, 24, $245-847$.

Levin, A. P., Albert, L., Besser, A., Smith, D., Zelenski, A., Rosenkranz, S., \& Neria, Y. (2011). Secondary traumatic stress in attorneys and their administrative support staff working with trauma-exposed clients. The Journal of Nervous and Mental Disease, 199, 946-955.

Livingston, W. L. (2002). Psychology and the law: De-stressing the profession, Michigan Bar Journal, 81 (October), 24-27.

Lloyd, C., \& Hays, J.R. (2008). Psychological distress and substance abuse: Recognizing problems and finding help. Houston Lawyer, 45 (March/April), 42-45.

Lu, R., \& Brody, D. (2019). The impact of serious occupational stress on indigent defense attorneys. Criminal Law Bulletin, 55, 30-49.

Ludick, M., \& Figley, C. M. (2016). Toward a mechanism for secondary trauma induction and reduction: Reimagining a theory of secondary traumatic stress. Traumatology, 23, 1-12.

Lynch, D. R. (1997). The nature of occupational stress among public defenders. Justice System Journal, 19, 17-35.

Lynch, D. R. (1998). In their own words: Occupational stress among public defenders. Criminal Law Bulletin, 34, 473-496.

Marmar, C., Weiss, D., Metzler, T., Ronfeldt, H., \& Foreman, C. (1996). Stress responses of emergency services personnel to the Loma Preita earthquake interstate 880 freeway collapse and control traumatic incidents. Journal of Traumatic Stress, 9, 63-85. 
Mclntyre, L. J. (1987). Public defenders: The practice of law in the shadow of dispute. Chicago: University of Chicago Press.

Murdoch, L. L. (2000). Psychological consequences of adopting a therapeutic lawyering approach: Pitfalls and protective strategies. Seattle University Law Review, 24, 483.

Murray, D. C., \& Royer, J. M. (2004). Vicarious traumatization: The corrosive consequences of law practice for criminal justice and family law practitioners. Legal Profession Assistance Conference. Dalhousie University, Halifax, Nova Scotia, Canada.

Norris, C. M. \& Deeley, L. (2014). Stress: The lawyer's 21st century epidemic, Hawaii Bar Journal, 18 (December), 20-21.

Norton, L., Johnson, J., \& Woods, G. (2015). Burnout and compassion fatigue: What lawyers need to know. UMKC Law Review, 84, 977-1002.

Ogletree, C. J. (1993). Beyond justifications: Seeking motivations to sustain public defenders. Harvard Law Review, 106, 1239-1294.

Organ, J. M. (2011). What do we know about the satisfaction/dissatisfaction of lawyers? A metaanalysis of research on lawyer satisfaction and well-being. University of St. Thomas Law Journal, 8, 225-74.

Osofsky, J. D., Putnam, F. W., \& Lederman, C. S. (2008). How to maintain emotional health when working with trauma. Juvenile \& Family Court Journal, 59, 91-102.

Otey, B. S. (2014). Buffering burnout: Preparing the online generation for the occupational hazards of the legal profession. Southern California Interdisciplinary Law Journal, 24, 147-201.

Patel, J., \& Patel, P. (2019). Consequences of repression of emotion: Physical health, mental health and general well-being. International Journal of Psychotherapy Practice and Research, 1, 1621.

Patel, K. A. Rajderkar, S. S., \& Naik, J. D. (2012). Occupational stress and burnout as predictors of job satisfaction amongst lawyers in District Sangli. National Journal of Medical Research, 2, 141-144.

Piwowarcyzy L., Ignatius S., Crosby S., Grodin M., Heeren T., \& Sharma, A. (2009). Secondary trauma in asylum lawyers. Bender's Immigration Bulletin, 14: 263-269.

Schenker, M. B., Eaton, M., Green, R., \& Samuels, S. (1997). Self-reported stress and reproductive health of female lawyers. Journal of Occupational and Environmental Medicine, 39, 556-568.

Silver, M. A., Portnoy, S., \& Peters, J. K. (2015). Stress, burnout, vicarious trauma, and other emotional realities in the lawyer/client relationship. Touro Law Review, 19 (4), 847-873.

Sweeney, M. J. (1999). Stress - An occupational hazard. Rhode Island Bar Journal, 47 (June), 25- 26.

Tennant, C. (2001). Work-related stress and depressive disorders. Journal of Psychosomatic Research, 51, 697-704.

Thornhill, R. B. (2017). Lawyer stress. Alabama Lawyer, 78 (March), 115-121.

Turnbull Jr., J. R. (2002). Lawyers helping lawyers: Help when you need it. South Carolina Lawyer, 4 (September/October), 14-18.

Vrklevski, L. P., \& Franklin, J. (2008). Vicarious trauma: The impact on solicitors of exposure to traumatic material. Traumatology, 14, 106-118.

Warren, D. (1998). Justice Frankfurter: The laws of stress and performance, Montana Lawyer, 23 (June), 5-10.

Wice, P. (2005). Public defenders and the American justice system. Santa Barbara, CA: Praeger. 
Journal of Criminal Justice and Law:

\section{Authors' Biographies}

Elizabeth Dotson, MA, MS, is a PhD Candidate at Washington State University. Ms. Dotson's research experience includes serving as study manager for a member of quantitative and qualitative projects conducted at the Simulated Hazardous Operational Task Laboratory at the WSU. These studies include projects examining the effects of shift work on operational performance, police mental health, and police performance in simulator scenarios involving deadly force decision making. Additional research projects with other labs include the examination of secondary stress and burnout in public defenders as well as looking at the influence of marijuana legalization on the occurrence involuntary civil commitments. She has presented research at national conferences including ACJS, ASC, and APLS.

David C. Brody, PhD, is a professor in the Department of Criminal Justice and Criminology at Washington State University. He received a JD from the University of Arizona College of Law and a PhD in Criminal Justice from the State University of New York at Albany. He is the author of casebooks on criminal law and criminal procedure, and over twenty scholarly articles that have been published in such journals as the American Criminal Law Review, Journal of Contemporary Criminal Justice, Hastings Women's Law Journal, Crime and Delinquency, and Judicature. He is a member of the WSBA Committee on Public Defense, and has served as the technical advisor for the Washington State Jury Commission, chair of the subcommittee on Judicial Selection and Evaluation of American Judicature Society's Washington Chapter, Legal Notes Editor for the Justice System Journal, and on the Board of Directors of the American Jury Institute. David's research focuses on judicial selection and evaluation, jury reform, the effect of social capital on the criminal justice system, and the interaction between law and criminal justice policy. He has made dozens of presentations at professional conferences and Continued Legal Education seminars. David has recently developed model survey instruments for the American Bar Association for use with the ABA Judicial Performance Evaluation Guidelines, and is currently working with several county bar associations in Washington state on developing and implementing judicial performance evaluation programs for trial court judges.

Ruibin Lu, PhD, is an Assistant Professor of Criminal Justice and has taught at Stockton University since the fall of 2018. Lu earned her bachelor's degree in law from Nankai University, Tianjin, China in 2012 and earned her Ph.D. in criminal justice and criminology from Washington State University in 2018. Lu teaches Courts, Law, and Procedure, Judicial Process, and Research and Evaluation in Criminal Justice. Her research focuses on specialty courts, U.S. judicial system, drug and alcohol use, policy evaluation, community corrections, and comparative criminal justice. Her work has been published in Journal of Drug Issues, Criminal Law Bulletin, Police Quarterly, International Journal of Offender Therapy and Comparative Criminology, Criminal Justice Review, The Police Journal: Theory, Practice, and Principles, and Journal of Ethnicity in Criminal Justice. 